\title{
POPS: the 60MW power converter for the PS accelerator: Control strategy and performances
}

Fulvio Boattini; Jean-Paul Burnet; Gregory Skawinski

CERN, Geneva, Switzerland,

Keywords: « NPC 3-level converters », « pulsed power supply », « particles accelerator »

\begin{abstract}
The main power supply of Proton-Synchrotron (PS) accelerator is one of the biggest at CERN. The old rotating machine system has been replaced with a new NPC based DC/DC power supply named POPS (Power system for PS main magnets) with capacitor banks as energy storage mean. POPS is in operation since February 2011. The operation of the PS accelerator requires a specific design of the control system with very high performance requirements in term of accuracy and precision. This paper describes the main lines of the control strategies analyzing the problems encountered and the solutions adopted. The performances of the converter are presented throughout the paper.
\end{abstract}

Presented at: EPE 2015, 7-10 September 2015, Geneva, Switzerland

Geneva, Switzerland

October, 2015 


\section{POPS: the 60MW power converter for the PS accelerator: Control strategy and performances}

Fulvio Boattini; Jean-Paul Burnet; Gregory Skawinski;

CERN, European Organization for Nuclear Research

1211 Geneva 23, Switzerland

Tel: +41 227678542

fulvio.boattini@cern.ch, jean-paul.burnet@cern.ch; g.skawinski@cern.ch

http://www.cern.ch

\section{Keywords}

« NPC 3-level converters », " pulsed power supply », " particles accelerator »

\section{Abstract}

The main power supply of Proton-Synchrotron (PS) accelerator is one of the biggest at CERN. The old rotating machine system has been replaced with a new NPC based DC/DC power supply named POPS (Power system for PS main magnets) with capacitor banks as energy storage mean. POPS is in operation since February 2011. The operation of the PS accelerator requires a specific design of the control system with very high performance requirements in term of accuracy and precision. This paper describes the main lines of the control strategies analyzing the problems encountered and the solutions adopted. The performances of the converter are presented throughout the paper.

\section{Introduction}

The CERN PS accelerator is part of the LHC injection chain. It is constituted by 101 magnets connected in series for a total impedance of $0.9 \mathrm{H}$ and $0.32 \Omega$. This pulsating machine accelerates proton or ion beams on their way to the LHC (Large Hadron Collider) but also for some other experiments where different beam energies are required.

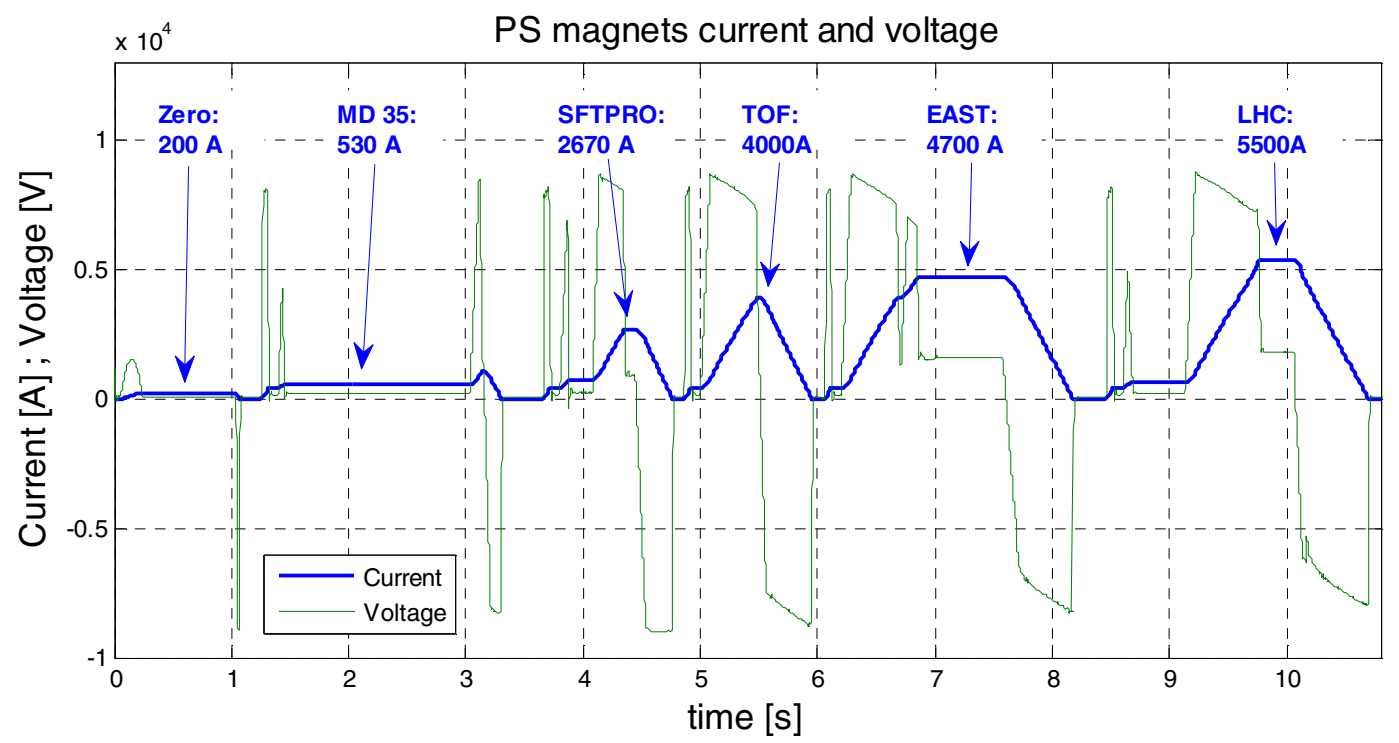

Figure 1: Current pulses in the PS intended for different experiments (Measurements).

Figure 1 shows the six different current pulses that are presently generated in the PS accelerator in ascending order of peak current from $200 \mathrm{~A}$ to $5500 \mathrm{~A}$. These cycles are organized in a super-cycle where some or all of them are mixed together and continuously executed with a periodicity of $1.2 \mathrm{~s}$ by the PS main power supply. Given the mainly inductive nature of the load the power supply system utilizes an energy 
storage mean that allows decoupling the instantaneous power required by the load from that taken by the AC network.

The previous power system (a rotating machine with fly-wheel) has been replaced in 2010-2011 by the $60 \mathrm{MW}$ POPS power converter [1] where 6 capacitor banks are used as energy storage elements $(6 \mathrm{x} 0.247 \mathrm{~F}$ in total). The topology of POPS is illustrated in Figure 2.

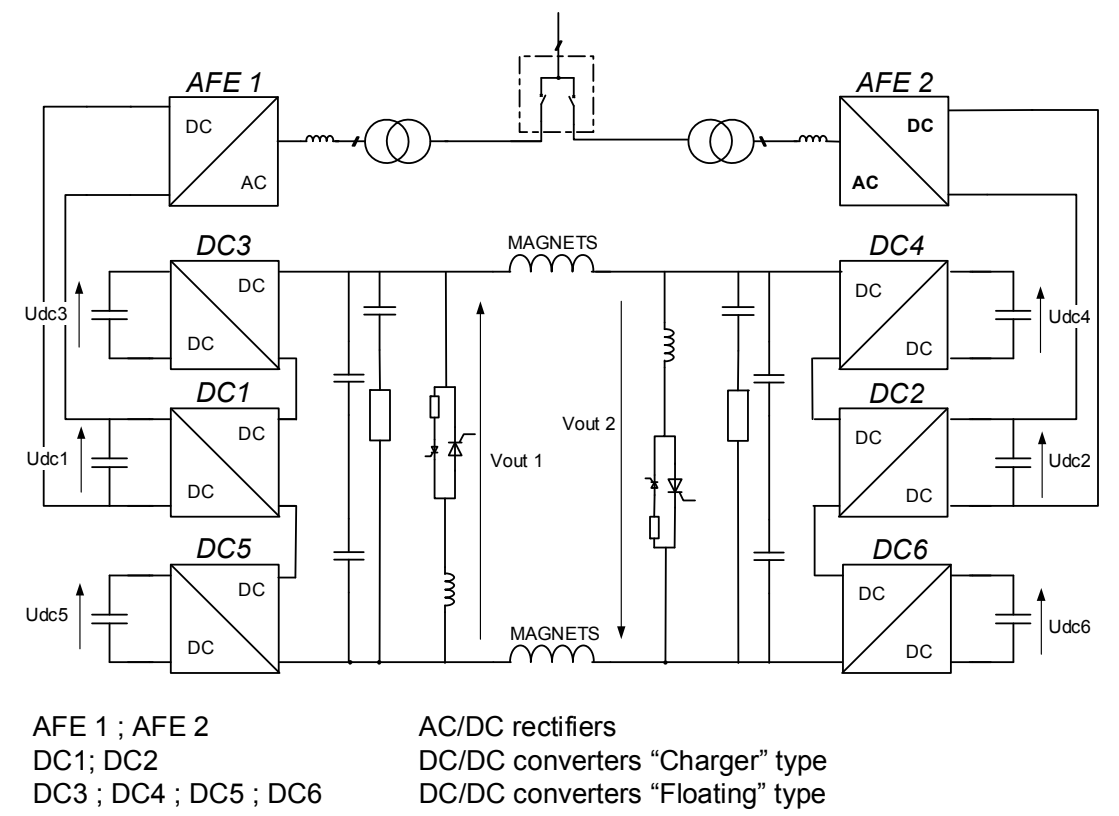

Figure 2: POPS power system layout

It is composed of two identical AC/DC (Active Front End, AFE) units which supply power to six DC/DC power converters (4 floating and 2 chargers). The DC/DC converters are designated as "Floatings" if the relative capacitor bank is floating otherwise "Chargers" when an AFE is present. This distinction is of the utmost importance for the converter control strategy as we will see later on.

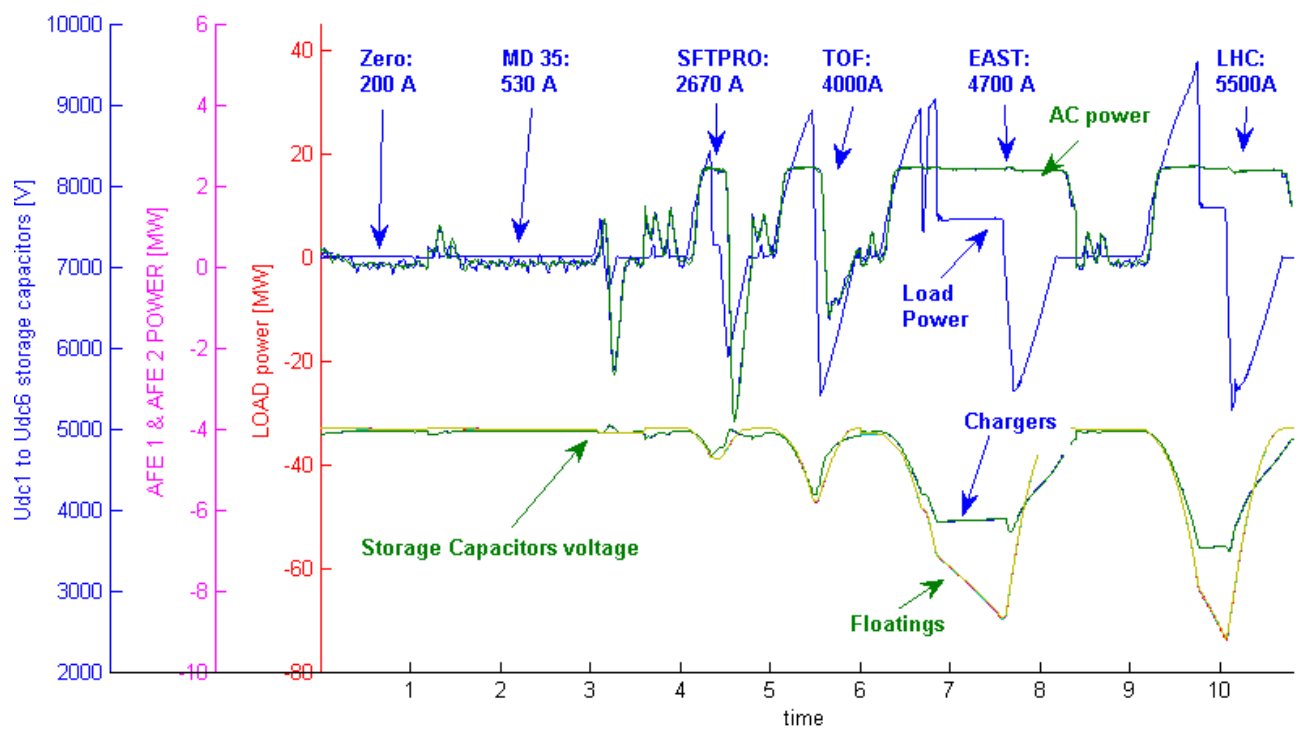

Figure 3: POPS capacitors discharge and AFE voltages during cycles

The system is designed to generate $6 \mathrm{kA}$ peak current with $10 \mathrm{kV}$ peak voltage, from where the $60 \mathrm{MW}$ peak power stems. The capacitor banks are used to exchange the energy with the PS magnets during converter pulsing operation [2]. As the current in the magnets rises, the voltage across storage capacitors drops. The energy stored in the magnets is then given back to capacitors at the end of the cycle (Figure 3). In this way the AFE converters provide only the losses required by the magnets and the converter itself. 


\section{POPS control requirements}

The main task of the POPS control system is to track very accurately the reference signal (Bref or Iref) coming from CERN control center. The global performance is determined by stability of the particles beam. Several packets of particles (bunches) circulate inside the PS ring at the same time. The tiniest perturbation of the magnetic field (Bfield) can lead to instability and loss of the beam control.

This is particularly true during particle injection and extraction (Figure 4)

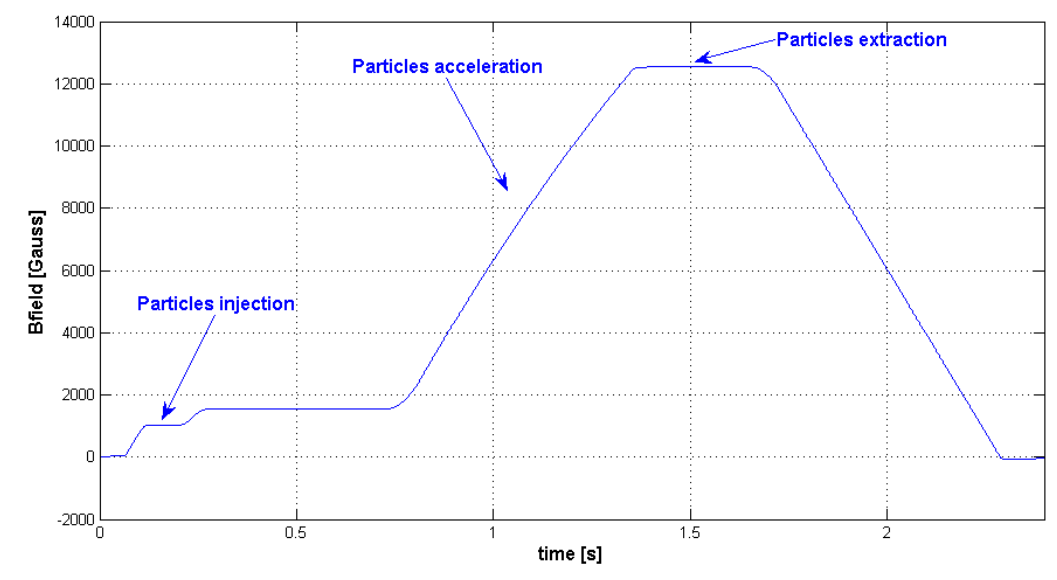

Figure 4: Accelerating cycle

During these two moments it is required that the field is stable and accurate within a limitation of less than $\pm 10 \mathrm{ppm}$. When translating this requirement into voltage accuracy we get the astonishing values of respectively:

- $20 \mathrm{mV}$ : output voltage accuracy during injection flat-top;

- $180 \mathrm{mV}$ : output voltage accuracy during extraction flat-top.

These values are particularly challenging to be obtained with a $\pm 10 \mathrm{kV}$ power converter particularly when considering that the magnetic field must be accurate and stable all along the flat top as long as injection and extraction continue.

Once particles are kicked off the PS accelerator, a new accelerating cycle with new injected particles can start. During the last phase of the cycle all control performance requirements can be released as particles are no more in the accelerator and priority is given to the recharging of the storage capacitor voltages.

This is the other important challenge of the control system. Floating capacitors uses the magnet current for their recharge and they must return to their nominal voltage before the end of the current cycle, to be able restarting a new cycle.

\section{POPS control layout}

The POPS control system is schematically represented in Figure 5.

An external loop is responsible for magnetic field regulation and calculates the reference voltage $V_{\text {REF }}$ for the next voltage regulation loop. The voltage regulation loop is responsible for generating the total output voltage reference $\mathrm{V}_{\text {OUTREF }}$ used by the voltage reference allocation module to calculate the references of each DCDC converter $\mathrm{V}_{\text {REF_DCDC_X. }}$. 


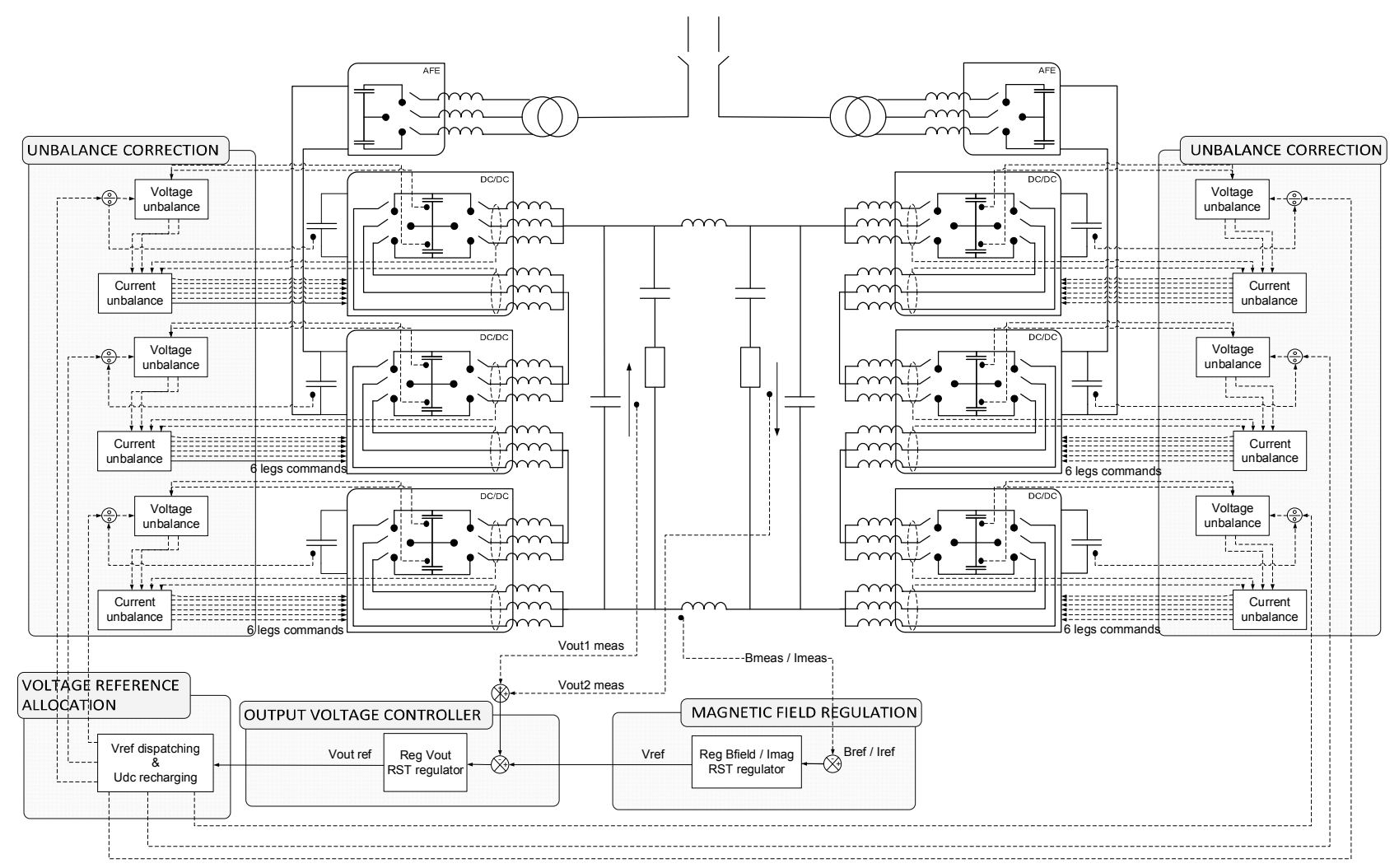

Figure 5. POPS control layout

The six $\mathrm{V}_{\text {REF DCDC } \mathrm{x}}$ are then further modified to account for voltage and current unbalance correction resulting in six references for each DCDC converter (i.e. one for each leg), $\mathrm{V}_{\text {REF_DCDCX_LEGY. }}$

Figure 6 shows the POPS control hardware; the FGC (Function Generator and Controller) is responsible for the acquisition of the magnetic field reference and measurement and for the execution of the $\mathrm{B}_{\text {field }}$ regulation loop. The FGC is also responsible for the synchronization of the complete control system. All other functionalities are executed by the main controller.

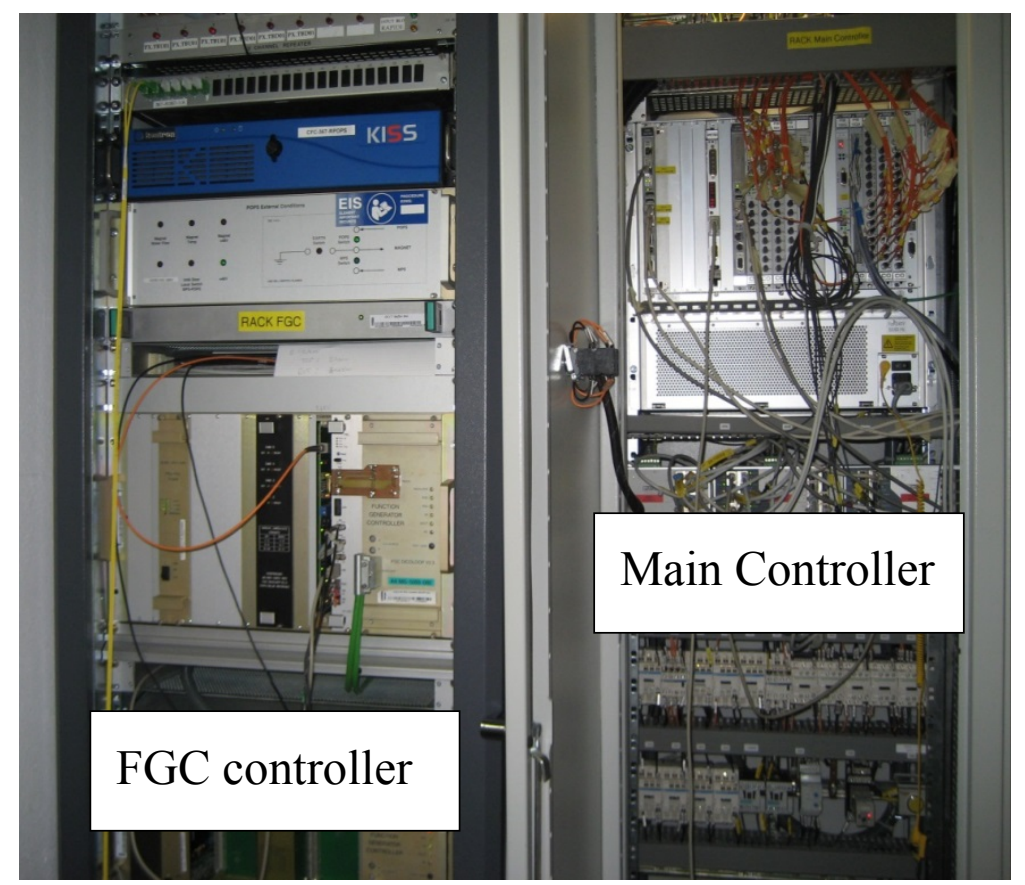

Figure 6. POPS control hardware 


\section{Vout control loop}

The system to be controlled is the output filter (Figure 7).

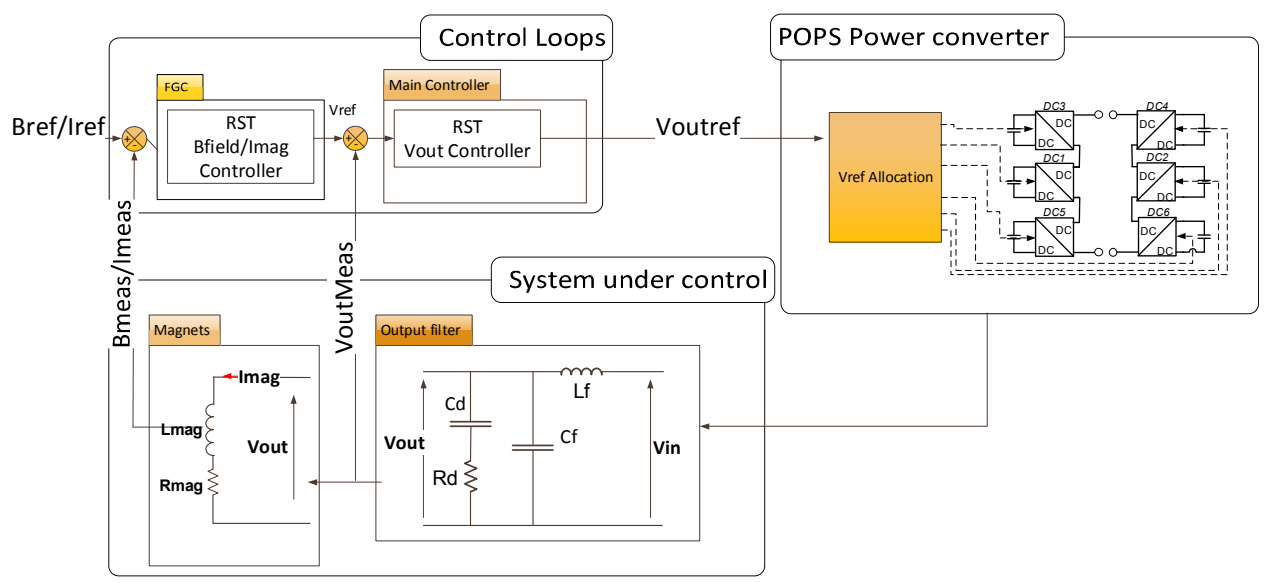

Figure 7. POPS control loops

$$
F L T_{T F}=\frac{R d \cdot C d \cdot S+1}{L f \cdot C f \cdot R d \cdot C d \cdot S^{3}+L f \cdot(C f+C d) \cdot S^{2}+R d \cdot C d \cdot S+1} \cdot e^{-s \cdot 0.0023}
$$

It can be represented by a third order transfer function with a pure delay of $2.3 \mathrm{~ms}$ as a consequence of the response of measurements and digital filtering.

RST control polynomials are calculated with the procedure described in [4]. Once a first set of coefficients is available, system identification is used to more accurately model the output filter transfer function. This has been done by using the voltage output response during the initial (fastest) part of a typical LHC cycle (Figure 8).

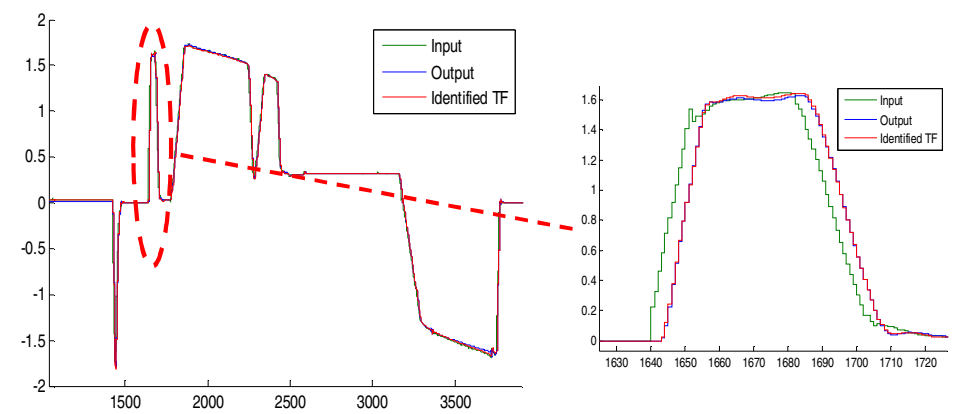

Figure 8. POPS voltage response for identification

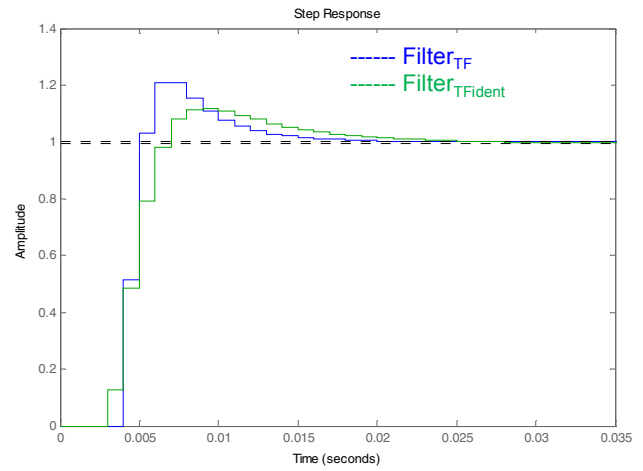

Figure 9. Filter identified Vs Theoretical step response

Once identified, the output filter has the transfer function reported in (2).

Filt $_{\mathrm{TFd}} \mathrm{dident}=\frac{0.1247 \cdot \mathrm{z}^{-3}+0.1379 \cdot \mathrm{z}^{-4}-0.2145 \cdot \mathrm{z}^{-5}}{1-1.799 \cdot \mathrm{z}^{-1}+1.063 \cdot \mathrm{z}^{-2}-0.2156 \cdot \mathrm{z}^{-3}}$

The identified transfer function (2) looks quite different from the theoretical one (Figure 9). The new transfer function is used to recalculate a new set of RST coefficients. The final performances are reported in Figure 10 and Figure 11. The loop has a $160 \mathrm{~Hz}$ bandwidth for reference following and $83 \mathrm{~Hz}$ for disturbance rejection. 


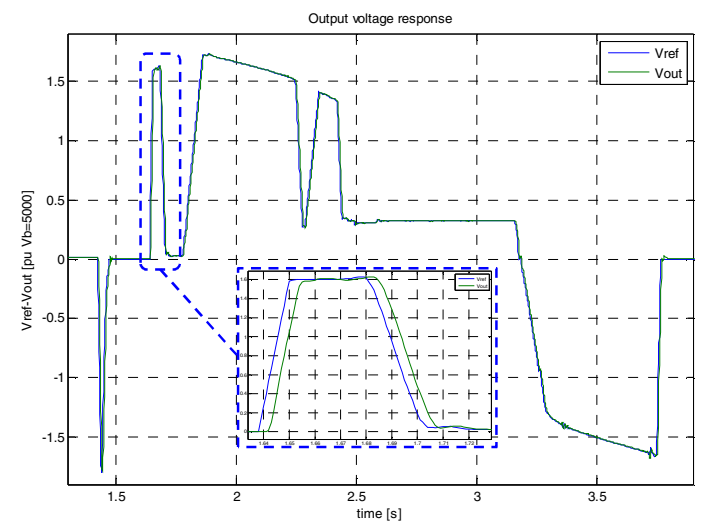

Figure 10. Output Voltage Loop response

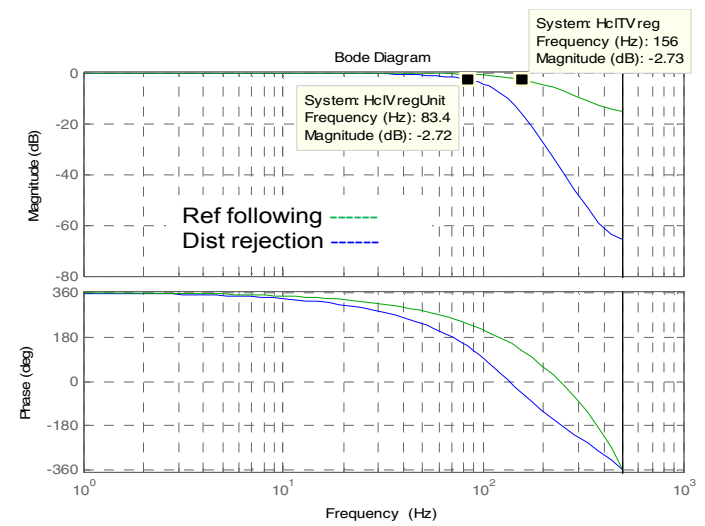

Figure 11. Bode of output voltage closed loop

\section{Bfield / Imag regulation loop}

The outer loop is the Bfield or Imag controller. Depending upon the cycles, the controller has to run either in B-field or I-mag mode to suit the different control tasks. The magnet transfer function is a first order (L-R circuit) (3).

$\begin{aligned} \operatorname{Mag}_{\mathrm{Bf}} & =\frac{1}{\mathrm{sF} \cdot \mathrm{K}_{\mathrm{m}}+\frac{\mathrm{R}_{\mathrm{m}}}{\mathrm{L}_{\mathrm{m}}} \mathrm{K}_{\mathrm{m}}} \\ \operatorname{Mag}_{\mathrm{Im}_{\mathrm{TF}}} & =\frac{1}{\mathrm{~s} \cdot \mathrm{L}_{\mathrm{m}}+\mathrm{R}_{\mathrm{m}}}\end{aligned}$

Although the time constant of the magnets is much lower than the filter response time, the extremely high accuracy demanded by the control, forced us to consider the complete transfer function of the filter and magnets integrated, for the calculation of control parameters.

Since the execution cycle time of the loops is different ( $3 \mathrm{~ms}$ for the Bfield and $1 \mathrm{~ms}$ for the Vout controller), we determined a continuous time transfer function for the two systems as the product of (3) \& (4) and then transformed into the discrete transfer function.

We use identification in order to derive the equivalent transfer function for the Vout control loop (Figure 12).

VoutLoop $_{\text {ident }}=\mathrm{e}^{-0.0012 \cdot \mathrm{s}} \cdot \frac{-3.365 \cdot \mathrm{s}+1.652 \mathrm{e} 6}{\mathrm{~s}^{2}+2046 \cdot \mathrm{s}+1.652 \mathrm{e} 6}$

After making the RST calculation as for the Vout loop, we get the performances reported in (Figure 13). The loop has an $85 \mathrm{~Hz}$ bandwidth for reference following and $30 \mathrm{~Hz}$ for disturbance rejection.

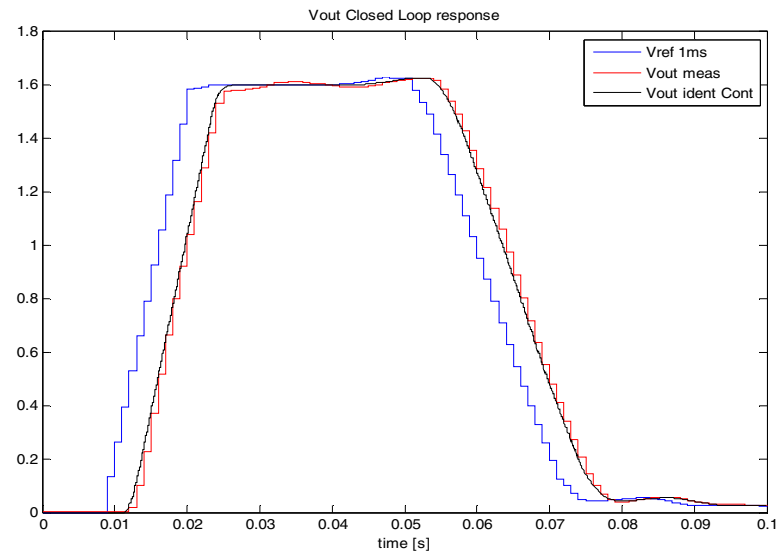

Figure 12. Identification of Vout control loop

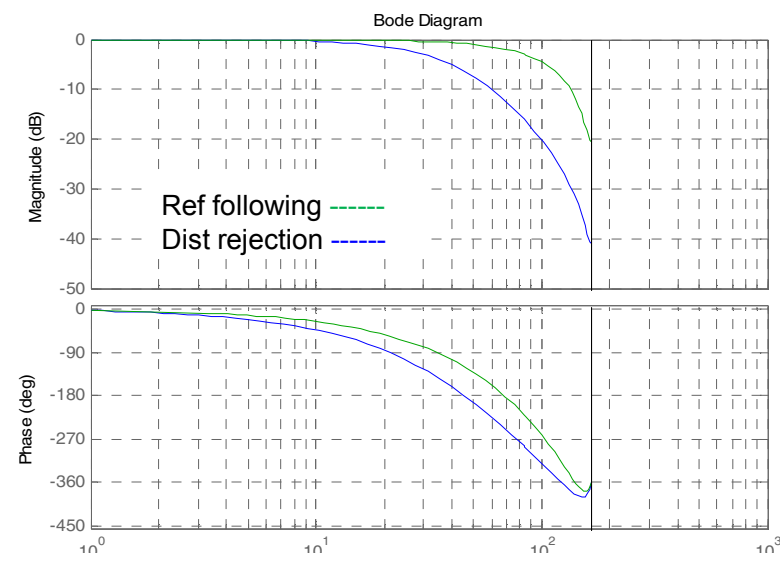

Figure 13. Bode of Bfield closed loop 


\section{Voutref allocation among DCDC converters}

Once the Vref is generated by the control loops, it must be distributed among all the six converters connected in series (Figure 2). This allocation is crucial and must be effectuated taking into consideration the following aspects:

- Accuracy of $10 \mathrm{ppm}$ must be guarantee all along the beam cycle when particles are charged in the PS ring

- All capacitor banks must be recharged at their nominal voltage $(5 \mathrm{kV})$ before a new cycle is restarted.

\section{A. Minimum IGBT conduction time}

With respect to the voltage accuracy and precision requirement it is mandatory to mention an important limitation of high power semiconductors related to the minimum time that they need to stay ON before a turn-off can actually be executed. This turned out to be a problem for POPS as the Tmin is in the order of 20us, which with the present PWM frequency and the voltage of the DC bus Udc, gives a minimum Vout to be generated by the converter, in the order of $200 \mathrm{~V}$ which is higher than the injection flat-top required voltage.

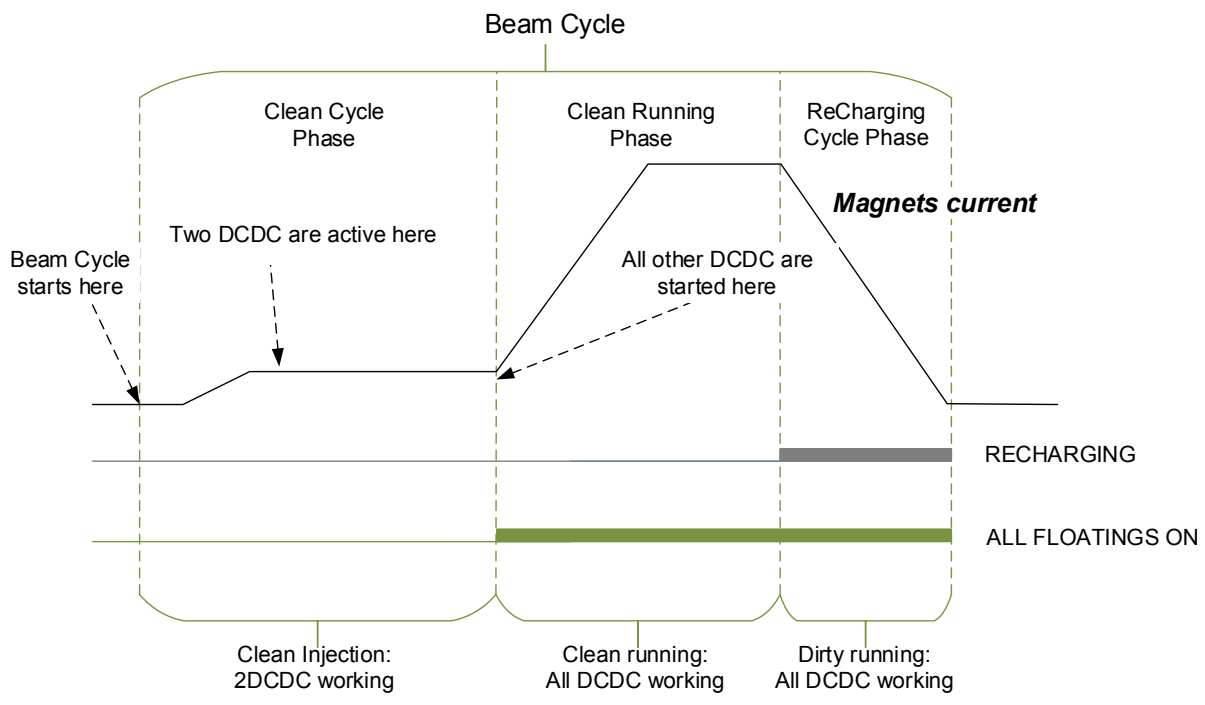

Figure 14. Beam Cycle control phases

To avoid having too high voltage ripple during this very critical phase, each beam cycle is started by using only two DCDC converters. In this way, the minimum voltage that the converter can generate is $67 \mathrm{~V}$, lower than the minimum required voltage. When the output voltage starts to increase all other DCDC converters are turned on until the end of the cycle.

\section{B. Vref distribution}

During the "injection phase" (Figure 4), the total reference is divided in two identical contributions each one assigned to a DCDC converter on both sides of the POPS output filters.

$\operatorname{Vref}_{\mathrm{C}}=\frac{\text { Vref }}{2}$

$\operatorname{Vref}_{\mathrm{F}}=0$

Vref $_{\mathrm{F}}=$ Reference voltage for the floating converters

Vref $_{\mathrm{C}}=$ Reference voltage for the charging converters

When all DCDC converters are active a different criteria is used based on the energy utilization factors of the storage capacitors. To derive these, we start from the total power given to the magnets by the POPS converter calculated as:

$\mathrm{P}(\mathrm{t})_{\mathrm{mag}}=\mathrm{V}_{\text {ref }} \cdot \mathrm{I}_{\mathrm{mag}}=\left(\mathrm{V}_{\mathrm{L}}+\mathrm{R}_{\mathrm{m}} \cdot \mathrm{I}_{\mathrm{mag}}\right) \cdot \mathrm{I}_{\mathrm{mag}}$

The Vref can therefore be considered as the sum of the resistive voltage drop of the magnets, plus the inductive voltage. The main criteria for the repartition of the Vref is to give the "Floatings" only a portion 
of the inductive part of the Vref, leaving the losses and the remaining part of the voltage to the "Chargers". The inductive part is in-fact released by the magnets when the current ramp down and can therefore be used to recharge the "Floatings" capacitors.

"Chargers" can provide the losses of the magnets, since they are connected to the grid. They can also compensate for the missing charge at the end of the cycle. Vref is then distributed according to (13).

$$
\begin{aligned}
& \mathrm{E}_{\mathrm{F}}=\mathrm{k} \cdot\left(\mathrm{Udc}_{\text {max } \_\mathrm{F}}^{2}-\mathrm{Udc}_{\text {min_F }}^{2}\right) \\
& \mathrm{E}_{\mathrm{C}}=\mathrm{k} \cdot\left(\mathrm{Udc}_{\max \_\mathrm{C}}^{2}-\mathrm{Udc}_{\text {min } \_\mathrm{C}}^{2}\right) \\
& \mathrm{E}=\mathrm{E}_{\mathrm{F}}+\mathrm{E}_{\mathrm{C}} \\
& \mathrm{K}_{\mathrm{F}}=\frac{\mathrm{E}_{\mathrm{F}}}{\mathrm{E}} \quad \mathrm{K}_{\mathrm{C}}=\frac{\mathrm{E}_{\mathrm{C}}}{\mathrm{E}} \\
& \mathrm{V}_{\text {ref }}=\mathrm{V}_{-} \mathrm{ref}_{\mathrm{L}}+\mathrm{Vref}_{\mathrm{R}} \\
& \operatorname{Vref}_{\mathrm{F}}=\mathrm{K}_{\mathrm{F}} \cdot \frac{\operatorname{Vref}_{\mathrm{L}}}{\mathrm{nF}} \\
& \operatorname{Vref}_{\mathrm{C}}=\operatorname{Vref} \cdot \frac{\left(1-\mathrm{K}_{\mathrm{F}}\right)}{\mathrm{nC}}
\end{aligned}
$$

Where :

$\mathrm{E}_{\mathrm{F}}=$ Available energy in the floating capacitors

$\mathrm{E}_{\mathrm{C}}=$ Available energy in the charging capacitors

$\operatorname{Vref}_{\mathrm{L}}=$ Inductive contribution of reference voltage

Vref $_{R}=$ Resistive contribution of reference voltage

$\mathrm{n}_{\mathrm{F}} \mathrm{n}_{\mathrm{C}}=$ Number of floating and charging DCDC converters

\section{1) Capacitors voltage regulation}

In ideal conditions, given the Vref allocation, the floating capacitor voltages should return to their initial value. This is not happening, because during the flat-top of the beam cycle (particle extraction) the Vref $f_{\mathrm{F}}$ should be given the value of zero (7) while it is in-fact kept higher than the minimum on-time conduction of the semiconductors to avoid entering in the nonlinear mode of the power converter.

Before the cycle is over, all capacitors must be charged up to their nominal value. A new cycle is likely to restart soon after the present one so there is no additional time to complete the charge. Floating capacitors can only be recharged when the magnets' current is higher than zero.

To dynamically correct the recharge of floating capacitors, the control periodically estimates the time left before magnets' current reaches zero (Figure 15). The equation of the capacitor charge can be expressed as in (8).

$$
\begin{aligned}
& \mathrm{Udc}_{M A X}-\mathrm{Udc}_{0}=\frac{1}{\mathrm{Ccap}} \cdot \int_{0}^{\mathrm{DTend}} \mathrm{mfl} \cdot \operatorname{Imag} \cdot \mathrm{dt}=\frac{1}{\mathrm{Ccap}} \cdot \int_{0}^{\mathrm{DTend}} \mathrm{mfl} \cdot\left[\operatorname{Imag}_{0}-\frac{\mathrm{dI}}{\mathrm{dt}} \cdot \mathrm{t}\right] \cdot \mathrm{dt}= \\
& =\mathrm{mfl} \cdot \frac{1}{\text { Ccap }} \cdot \text { DTend } \cdot\left[\operatorname{Imag}_{0}-\frac{1}{2} \frac{\mathrm{dI}}{\mathrm{dt}} \cdot \text { DTend }\right]
\end{aligned}
$$

Where :

$\mathrm{Udc}_{M A X}=$ nominal capacitor voltage when recharged

$\mathrm{Udc}_{0}=$ Capacitor voltage value at the moment the calculation is performed (t0)

DTend $=$ Estimated time until current reaches zero from to

$\operatorname{Imag}_{0}=$ Magnets current value at the moment the calculation is performed (t0)

$\mathrm{mfl}=$ modulation index of the DCDC converter: $\mathrm{mfl}=\frac{\operatorname{Vref}_{\mathrm{FL}}}{\mathrm{Udc}}$

From (9) we get (10) and then (11) by replacing DTend $=\frac{\mathrm{Imag} 0}{\mathrm{dI} / \mathrm{dt}}$.

$$
\mathrm{mfl}=\frac{(\mathrm{Udcmax}-\mathrm{Udc} 0) \cdot \mathrm{Ccap}}{\text { DTend } \cdot\left(\mathrm{Imag} 0-\frac{1 \mathrm{dI}}{2 \mathrm{dt}} \mathrm{DTend}\right)}
$$

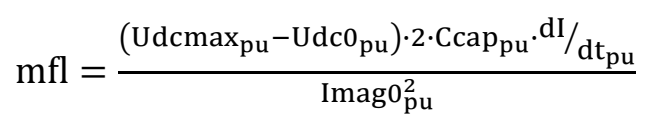

Where : Ccap $_{\mathrm{pu}}=$ Ccap $\cdot \frac{\text { Vbase }}{\text { Tc } \cdot \text { Ibase }} \quad \mathrm{dI} / \mathrm{dt}_{\mathrm{pu}}=\frac{\mathrm{dI}}{\mathrm{dt}} \cdot \frac{\mathrm{Tc}}{\mathrm{Ibase}}$ 


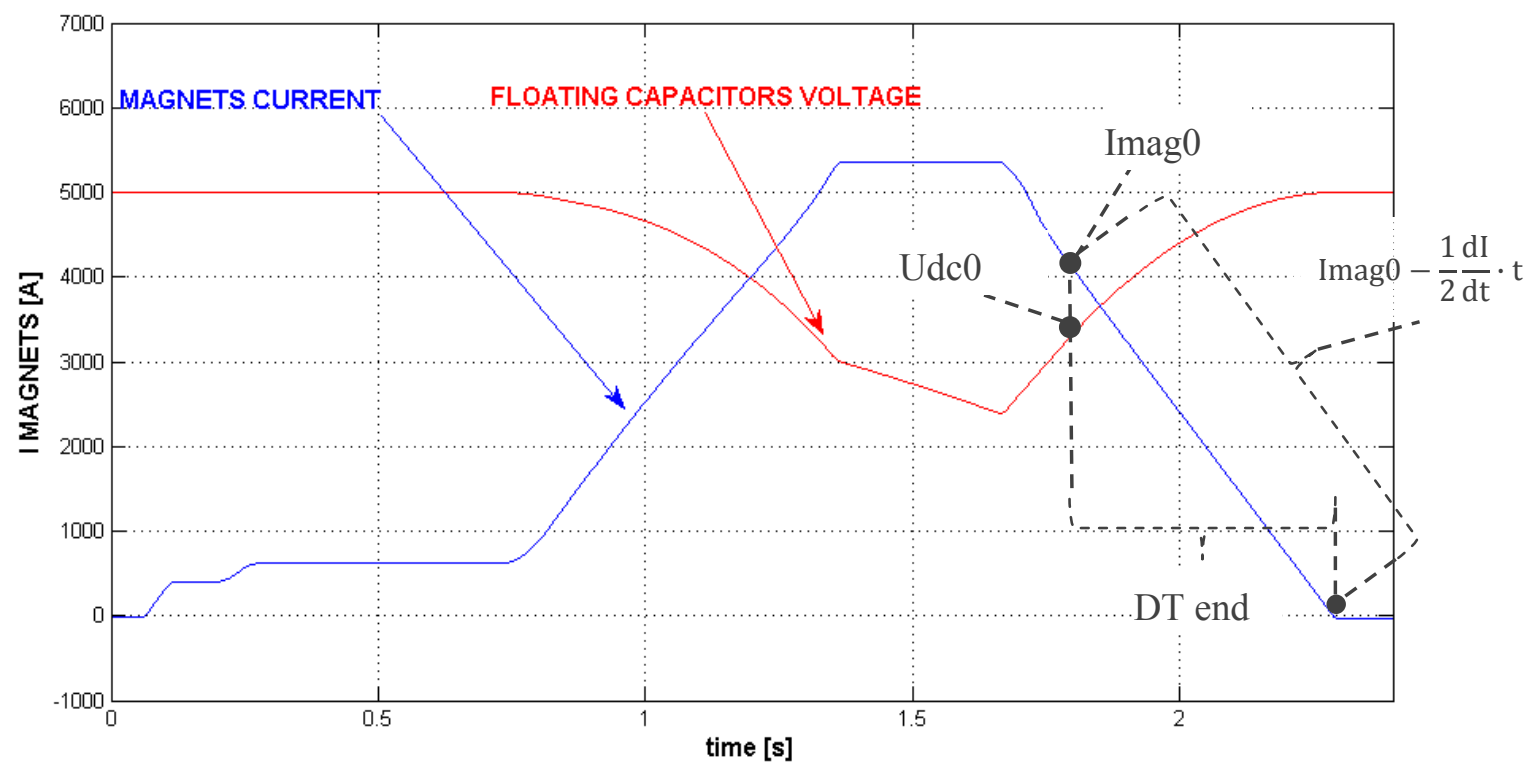

Figure 15: Estimation of time left before current reaches zero.

Then the voltage coefficients are calculated as follow:

$$
\operatorname{Vref}_{\mathrm{F}}=\mathrm{mfl} \cdot \mathrm{Udc}_{\mathrm{pu}} \quad \operatorname{Vref}_{\mathrm{C}}=\frac{\text { Vreftot }-\mathrm{N}_{\mathrm{F}} \cdot \operatorname{Vref}_{\mathrm{F}}}{\mathrm{N}_{\mathrm{C}}}
$$

Figure 16 shows the results with LHC cycle; when the POPS control enters into the recharging phase it gives priority to the recharging of the floating capacitors and the $\mathrm{Vref}_{\mathrm{FL}}$ is calculated according to (11) (the picture shows the modulation indexes as the $\mathrm{Vref}_{\mathrm{FL}}$ and $\mathrm{Vref}_{\mathrm{CH}}$ were not available in the measurement).

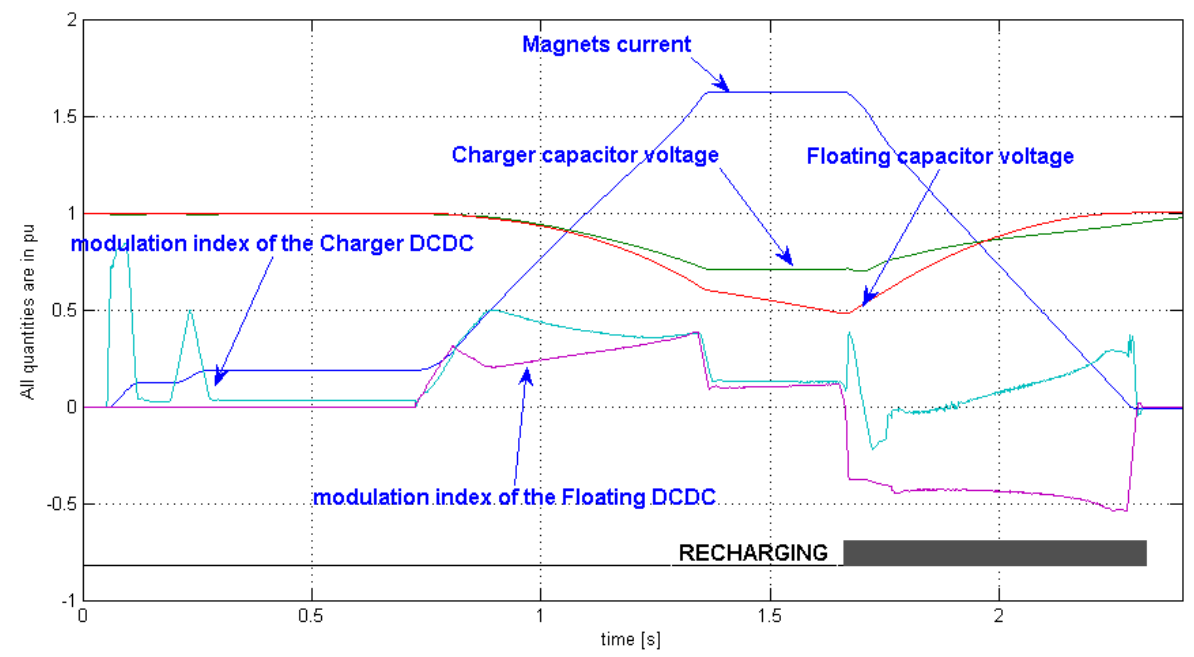

Figure 16. Capacitor banks recharging (per unit values)

We note that the modulation index of the charger converter rises a bit as eventually the total Voutref must be equal to that requested by the voltage controller. This contribution can be regulated by adjusting the initial estimation of the $\mathrm{dI} / \mathrm{dt}$ in (8) the first time the estimator is executed. 


\section{Performance results and conclusions}

The expected performances in the regulation of the Bfield have been achieved. Error! Reference source not found. shows the results of an LHC $26 \mathrm{GeV}$ cycle.
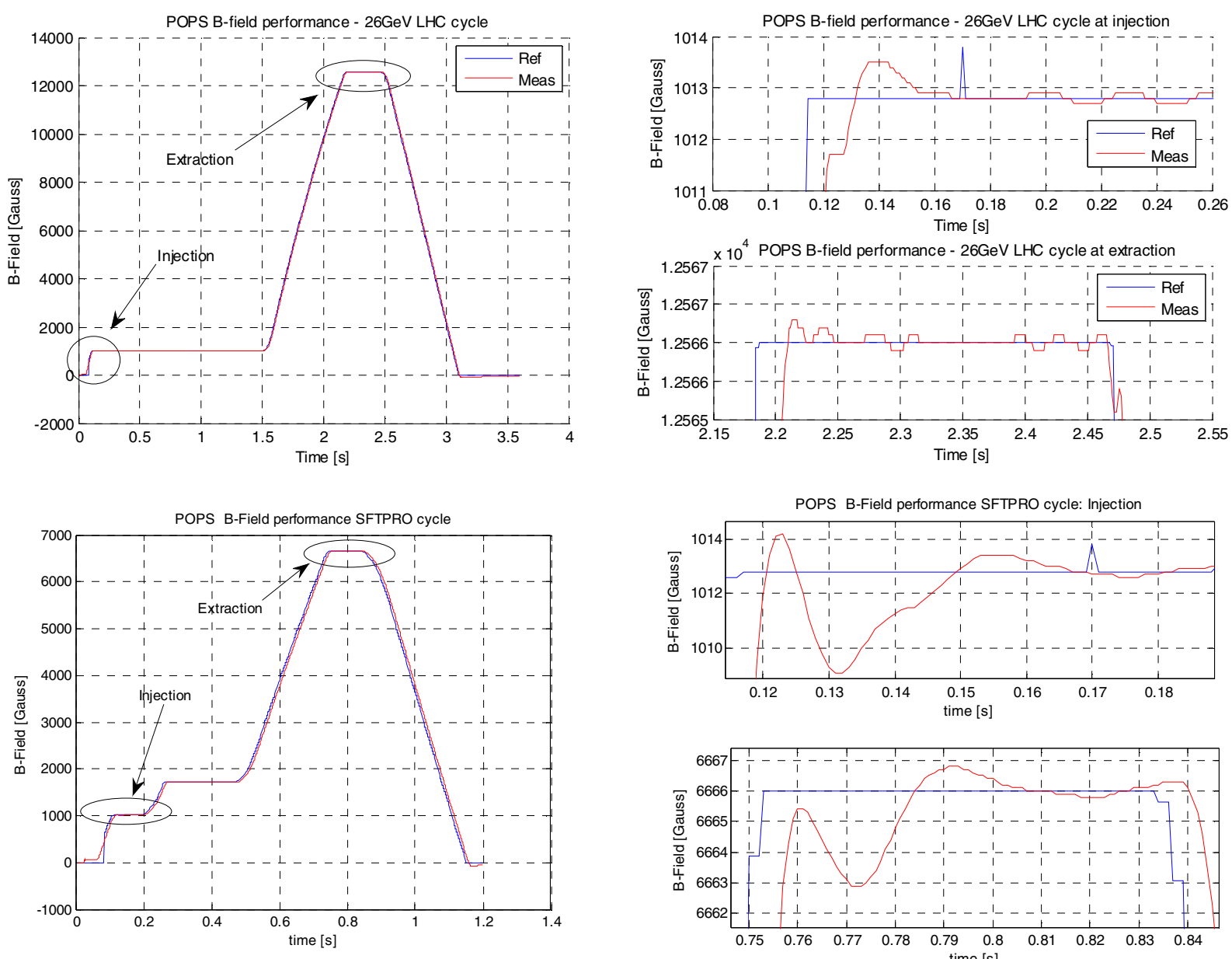

Figure 17. PS magnet B-field regulation performance: LHC (TOP) \& SFTPRO (BOTTOM)

For the LHC cycle the tracking error has been reduced to less than 0.5 Gauss over an absolute value of 12000 Gauss. With lower current cycles like the SFTPRO, the error is bigger up to 3-4 Gauss. This is still acceptable for the operation of the machine. Investigations are ongoing to understand how to improve the behavior of the controller at lower current cycles.

\section{Acknowledgements}

We would like to thanks Mr Daniel Girod, Mr Regis Peron and Dr. Martin Veenstra for their contribution with the design and commissioning of the POPS control.

\section{References}

[1] R. Péron, V. Guennegues, JL. Pouliquen, B. Gollentz, F. Bordry, JP. Burnet, 'Performances analysis of main components used in 60MW pulsed power supply for particle accelerator', EPE-2009, Barcelona

[2] F. Bordry, J.P. Burnet, C. Farhni, A. Rufer, "Device for supplying a load with an integrated energy storage", European Patent, EP1868279

[3] C. Farhni, A. Rufer, F. Bordry, J-P Burnet, "A Multilevel Power Converter with Integrated Storage for Particle Accelerators" Power Conversion Conference - Nagoya, 2007. PCC '07

[4] Ioan D. Landau, Gianluca Zito, "Digital Control Systems. Design, Identification and implementation".

[5] K. J. Astrom, Bjorn Wittenmark, "Computer controlled systems. Theory and design". 